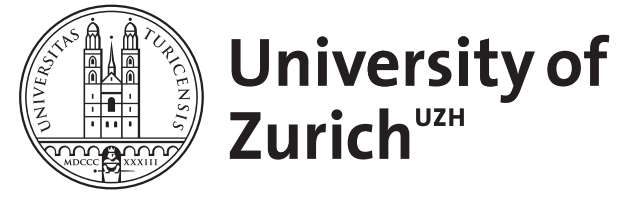

Zurich Open Repository and Archive

University of Zurich

University Library

Strickhofstrasse 39

CH-8057 Zurich

www.zora.uzh.ch

Year: 2015

\title{
Dimensions of Constitutive Ambiguity
}

Berndt, Frauke ; Sachs-Hombach, Klaus

DOI: https://doi.org/10.1515/9783110403589-011

Posted at the Zurich Open Repository and Archive, University of Zurich

ZORA URL: https://doi.org/10.5167/uzh-126385

Book Section

Published Version

Originally published at:

Berndt, Frauke; Sachs-Hombach, Klaus (2015). Dimensions of Constitutive Ambiguity. In: Winkler, Susanne. Ambiguity. Language and Communication. Berlin, Boston: De Gruyter, 271-282.

DOI: https://doi.org/10.1515/9783110403589-011 


\title{
Frauke Berndt \& Klaus Sachs-Hombach Dimensions of Constitutive Ambiguity
}

\begin{abstract}
Communication has the tendency to break down or to be misdirected. This happens especially in public communication, as the dramatic political conflicts at the beginning of the twenty-first century prove. If not caused by armed forces, these conflicts are usually produced by a concrete media event that triggers competing interpretations and often leads to unforeseeable consequences. In our paper we claim that the origin of such conflicts lies in the phenomenon of constitutive ambiguity. Its thorough exploration opens up a fundamental understanding of communication. Though it is considered a key issue in the humanities, we do not regard constitutive ambiguity as a mistake to be pragmatically rectified. In its inevitability, constitutive ambiguity rather unlocks a field of possibilities, the use of which is apt to even provide evolutionary advantages. In our paper we will give an overview, relating three types of ambiguity to a variety of notions used in linguistics, consider the medial forms of ambiguity, and differentiate the semantic levels of ambiguity, particularly commenting on the pragmatic causes of constitutive ambiguity.
\end{abstract}

\section{Introduction}

Approximately 340 years ago, in 1668/69, Hans Jakob Christoffel von Grimmelshausen's Der abentheuerliche Simplicissimus Teutsch (The Adventurous Simplicissimus) was published in five books. One of the main events in the first book is the arrest of the protagonist, Simplicissimus, in Hanau, who is then brought before an officer:

\footnotetext{
I knew not if it were he or she: for he wore his hair and beard French fashion, with long tails hanging down on each side like horse-tails, and his beard was so miserably handled and mutilated that between mouth and nose there were but a few hairs, and those had come off so ill that one could scarce see them. And not less did his wide breeches leave me in no small doubt of his sex, being such that they were as like a woman's petticoats as a man's breeches. So I thought, if this be a man he should have a proper beard, since the rogue is not so young as he pretends: but if a woman, why hath the old witch so much stubble round her mouth? [...] So as I stood in doubt, knowing not of modern fashions, at last I held he was man and woman at once. (Grimmelshausen 1912, 64)
}

This scene revolves around the ambiguity of the person's attire (clothing, hair) as signs whose meaning is clearly dictated by fashion and, thus, negotiable. In 
a rhetorical sense, the soliloquy represents the device of expressing doubt (dubitatio): At first, Simplicissimus thinks the officer is a man, and then a woman. In order to finally solve the gender trouble, he chooses a third gender somewhere in between: a "mannish woman or this womanish man" (64). Simplicissimus continues to rely on this solution when conversing with the officer after his arrest: "Oh my good Hermaphrodite [...] leave me my little prayer-book," he begs the officer, who wants to take away his only belonging. But, as if having misheard or not understanding him correctly, the officer responds: "Thou fool [...] who the devil told thee my name was Hermann?” (65). This passage of dialogue is based on two overlapping semantic scripts or frames: the anthropological frame and the frame of the proper name. On the intradiegetic level of communication, Simplicissimus addresses the officer in jest, or in ignorance, as "(herm-)aphrodite" by using an anthropological classification as a proper name. It seems, however, as if the officer is also either especially ignorant or especially cunning. In his answer, he in turn conversely uses his proper name "Hermann" as an anthropological classification. As a result, he juxtaposes this anthropological type that connects something male (herm-) with something female (-aphrodite) to form 'hermaphrodite' in opposition to a type that combines something male (herm-) with something male (-mann) to form something one could argue is especially male (Hermann). In using this successful strategy, the officer corrects the manner in which Simplicissimus addresses him, as if to say: What was once a hermaphrodite is now a Hermann. The agreement reached between the two characters is based on the fact that Simplicissimus and the officer accept the "wrong" use of the proper name as the "right" anthropological classification. Because the reader is cleverer than these two characters (or at least they think they are), and because they do not want to subscribe to this agreement of disambiguation, the joke works on the extradiegetic level of outer communication. Unlike the two characters, the reader allows the two semantic levels, or frames, to overlap: the anthropological frame with the frame of the proper name. The resulting ambiguity suspends the disambiguation. The officer remains what he is: an ambiguous appearance whose gender identity cannot be determined without doubt.

This example leads to our central hypothesis that ambiguity is a characteristic feature of communication and a phenomenon which, in principal, cannot be avoided. It can only be influenced or controlled up to a certain degree. Although ambiguity has often been the focus of research in various disciplines (primarily in rhetoric, linguistics, art history, and literary studies), fundamental research in cultural anthropology is still much needed. Occasionally, double and multiple meanings are clearly caused by misunderstandings that can be resolved by clarifying the different (contextual) premises, but these are only specific phenomena. 
In principle, ambiguity is not a contingent but a constitutive dimension of communication.

As a method of cultural symbolization, ambiguity is necessarily conveyed through specific media. Accordingly, the analysis of phenomena of ambiguity does not lead to a general cultural anthropology but to a specific media anthropology. Ambiguity is hereby understood as a realm of possibility for each specific instance of communication conveyed through media. The analysis thereof does not aim to establish a catalogue of measures for avoiding ambiguities; the goal is rather to establish knowledge about the premises and mechanisms which are specific to different media and which make ambiguity a constitutive factor of communication and perhaps even (without giving away too much here) of evolution.

In order to better understand the phenomenon of constitutive ambiguity, we will begin with an overview of the different aspects of ambiguity by distinguishing between its different types, forms, and levels. We will refer to these three ways of diversifying the phenomenon of ambiguity as the dimensions of ambiguity. Insofar as these dimensions provide meaningful distinctions, a three-dimensional matrix can be designed, in which the variables entered would determine the different combinations of dimensions. The number of different phenomena of ambiguity can be, therefore, derived from the result of the possible combinations of categories. It is not our objective to accomplish the quite cumbersome task of actually creating this matrix in detail and filling it with examples, or to test whether each combination actually exists. Instead, we will illustrate how such a matrix could be built and organized.

In order to do that, we will, firstly, discuss the differences between the types of ambiguity according to Israel Scheffler, which we will, secondly, relate to several linguistic terms for phenomena of ambiguity. Thirdly, we will explain how we differentiate between various forms of realizations of ambiguity in media, before we will, fourthly, differentiate the semantic levels of ambiguity. As our main aim is to better understand the typology of constitutive ambiguity in its media-specific forms, we will discuss especially how constitutive ambiguity is realized on a pragmatic level with strategic communicative intentions. In the final section, this will serve as a basis for several evolutionary speculations. Overall, we are particularly interested in providing an overview of ambiguity in order to contribute to a better understanding of the connections between the different phenomena of ambiguity. 


\section{Types of Ambiguity (Israel Scheffler)}

Over the past few years, the concept of ambiguity has been reappraised in several fields, especially in art history (Eco 1989, Gamboni 2002, Krieger \& Mader 2010, Haverkamp 2012), linguistics (Ernst 2003), literary studies (Berndt \& Kammer 2009), and rhetoric (Bauer et al. 2010). Nevertheless, for the most part, ambiguity as a term relates to specific problems of each discipline. Ambiguity in communication is, therefore, just as ubiquitous as it is hard to grasp. As early as 1936, Richards already anticipated "ambiguity to the widest extent and of the subtlest kinds nearly everywhere" (Richards 1936, 40). The concept of ambiguity, hence, functions as a tentative category in the current humanities disciplines in cases where the epistemological interest in semiotic and interpretative systems is characterized by a mistrust of intellectual history's syntheses as well as dialectical reconciliations. The way this term has been used since the twentieth century can perhaps, thus, be interpreted as evidence of the (post)modern

change in thinking [...] that finds a way out of the back and forth of antitheses such as unity and multiplicity, continuity and discontinuity, subject and structures, lifeworld and system, and genesis and validity (Waldenfels 1987, 10)

And still, a general theory of ambiguity has yet to be developed. Such a theory would need to comprehensively clarify terminology that should include definitions to distinguish it from related phenomena (such as vagueness, polysemy, or ambivalence) in historical as well as systematic perspective. It should also include a typology of the concept. With regard to the classification of different types of ambiguity, we will refer to the American philosopher of language, Israel Scheffler, but will apply Scheffler's theory to the field of cultural anthropology, thereby modifying the nomenclature of types accordingly. Scheffler distinguishes between elementary ambiguity (e-ambiguity), interpretative ambiguity (i-ambiguity), and the phenomenon of multiple meaning (m-ambiguity). These types of ambiguity can be distinguished from vagueness and generality, as ambiguity is always based on concrete, competing meanings (Scheffler 1979, Fries 1980).

Relying on the perspective of cultural anthropology as a backdrop for the analysis of these phenomena, we will use the terms elementary, hermeneutic, and constitutive ambiguity in our systematization. According to Scheffler, elementary ambiguity occurs when a concrete sign has different meanings relative to the context of its use. This is the case for deictic expressions such as now, here, there, or, in the pictorial medium, for indices such as signposts, or arrows.

Not only has the second case, hermeneutical ambiguity, the same conditions as elementary ambiguity, but a concretely used sign must also have at least 
two competing meanings, both of which must independently be meaningful and adequate, but mutually exclusive. In this case, the alternative meanings are connected to the concretely used sign itself; they are, in a way, different lexical entries for the same sign. Ambiguity, thus, occurs when a context is insufficiently specified and does not (yet) allow one of the meanings to be chosen.

Both elementary and hermeneutic ambiguity have a partial character. The research of these two types usually focuses on the possibilities of disambiguation. Yet, the defining element for constitutive ambiguity is that the competing interpretations of each utterance always exist simultaneously. This type of ambiguity must be understood as part of a speech act, meaning that disambiguation would truncate or distort communication. According to Scheffler, our example of 'Hermann the hermaphrodite' is characteristic for the ambiguity that he refers to as multiple meaning (m-ambiguity) (Scheffler 1989). Both aspects of the appearance are contained simultaneously and discordantly in the sign being used. The person's attire (clothing, hair) does not depict a single, specific object; it exemplifies two aspects that are typical of different objects. The central issue we will focus on here will, therefore, be to explore the significance of this simultaneity of competing meanings.

\section{Linguistic Interface}

There are numerous linguistic terms that correlate to the distinctions discussed above. One term is, for instance, phonetic ambiguity (homophones, i.e. different words which are pronounced the same, such as I and eye), which is the equivalent of i-ambiguity in spoken language. We also find lexical ambiguity (homonyms, e.g. tackle in "Nice tackle!” (praising an act of tackling in sports, or, for example, fishing gear), which is the equivalent of i-ambiguity in spoken as well as written language. Morphological ambiguity (for example, a German history teacher (teacher of German history) vs. a German history teacher (German teacher of history)) is another linguistic term. Like orthographic ambiguity (homographs, e.g. desert (arid region) and desert (abandon)), morphological ambiguity is equivalent to i-ambiguity, but only in written language. All these cases are examples of i-ambiguity, as both meanings are competing, but only one of them is intended. Ambiguity, hence, only exists more or less theoretically and only as long as the meaning of the utterance has not yet become specific. When sufficient contextual information is provided, one of the two possibilities can then be chosen. When using the word tackle in the example above, we assume that either the act of tackling in a sport such as American football or rugby, or the equipment or gear 
used, for example, when fishing, is being referred to exclusively, and that this is not obvious to us because we only have limited access to the respective context.

These examples provide ample grounds to assume that many phenomena of ambiguity are interpretative ambiguities with media-specific forms. Elementary ambiguities, on the other hand, are regarded as false ambiguities because they generally are resolved quickly in their specific use, making it more or less part of their meaning to be context-sensitive. Therefore, we will not be taking elementary ambiguities into account in the following. It is interesting to note that, up to a certain degree, the tendency to dissolve double meaning also applies to interpretative ambiguities that are disambiguated in particular utterance situations through the specific utterance contexts, generally making them remain unnoticed within communication.

Let us now turn to other linguistic terms. In the case of the much emphasized structural or syntactic ambiguity (e.g., "He sees the man with the telescope.”), a sentence can clearly be said to have two competing meanings. This is also the case for ambiguity on the level of compositional semantics (e.g., "The two employees must be able to speak four languages.”). But is this the equivalent of m-ambiguity? Are there simultaneous, competing meanings here? Insofar as sentences such as these are actually uttered or intended ambiguously (e.g., "Flying planes can be dangerous."), the structurally and compositionally induced ambiguities rather seem to be connected to the phenomenon of multiple meaning. However, ambiguities such as these are generally also the unintended result of an insufficient syntactic and semantic determination of the language structure, which can be resolved accordingly by adding further contextual information. As a result, we believe that these are rather i-ambiguities. Presumably, they are closer to our example of 'Hermann the hermaphrodite', which is a clear case of m-ambiguity, because they are mereological ambiguities, in other words ambiguities that occur due to the different interpretations of the relationships between the part and the whole, which are typical and fundamental for the pictorial medium.

In the context of linguistic terms, clearly definable constitutive ambiguities exist only on the level of pragmatics. The sentence, The air is stuffy, is an example of m-ambiguity because - from the point of view of speech act theory - the illocutionary and/or perlocutionary function can both be interpreted differently while both are simultaneously intended. As to its illocutionary role, the sentence can be interpreted as information and as an appeal (e.g. to open the window). While both meanings do not necessarily exclude one another, they certainly exist simultaneously as independent meanings. Such constitutive ambiguities caused by pragmatics can be interpreted differently based on different models of communication. If, for instance, we use Schulz von Thun's model in our analysis, then we can distinguish between the aspects of content (information), relation, appeal 
(request), and self-revelation. According to Schulz von Thun (1981-1998), these aspects are always present simultaneously. Insofar as they entail and convey not only different aspects of communication but also sometimes competing messages, we are dealing with constitutive ambiguity.

Finally, we would like to refer to the term ambivalence in our discussion of the different types of ambiguity. Those complex phenomena of ambiguity that receive special public attention usually involve different assessments, in other words, ambivalence. To distinguish this from ambiguity, we will reserve the terms ambivalence or polyvalence respectively when referring to the phenomenon of competing assessments. A rose may seem ambivalent insofar as the flower is rated positive while the thorns are seen as negative. Ambivalence is, therefore, a subjective quality. It derives from the individual set of values that define the relationship between a person and an object. The ambiguity of 'Herman the hermaphrodite' is ambivalent insofar as the two characters in the novel agree that gender identity must be unambiguous and cannot be ambiguous. Thus, the "wrong" use of the proper name and the "right" use of anthropological classification both work to ease the gender trouble. We regard ambiguity as the central category here because ambivalences (arising from competing values) are caused by ambiguities (arising from competing interpretations). Indeed, we regard the phenomenon of ambiguity as fundamental, because the ambivalent assessment in communicative contexts is based on competing attributions of meaning.

Summing up, it should be noted that 1) the type of constitutive ambiguity (or multiple meanings) is primarily realized on the pragmatic level in a socially interesting way, but on this level it no longer seems to have the clarity of the lexically based ambiguity. In order to 2 ) better determine constitutive ambiguity, we should assume that we are generally dealing with ambiguity that is intended and intentionally used in a performative way, in other words, a form of strategic behavior.

\section{Media Forms of Ambiguity}

Communication is necessarily conveyed through media. Accordingly, ambiguity can only be researched in its media-specific forms. Speech (spoken language), text (written language), and image - and especially their respective multi-media connections to hybrid forms - are paradigmatic media forms of communication that are characterized through ambiguity in different ways. The discussion of the different types of ambiguity corresponding to existing linguistic terms has already shown that we can assume different media realizations for each type. The 
Latin expression incultoloco contains - when printed in the Latin scriptura continua - a written i-ambiguity (in culto loco vs. inculto loco). The English expression "there" is unambiguous in written form, but contains a phonetic i-ambiguity in a spoken utterance (it could be confused with "their"). In addition to the mediaspecific forms of spoken or written language, we also want to point out the mediaspecific forms of the image (Scheffler 1989). How do the different types of ambiguity correlate with their media forms? Is communication defined by different forms of ambiguity? And what is the specific quality of pragmatic ambiguity?

As already discussed above, we assume that a fundamental condition of communication is that communication processes are always connected to specific means of communication, in other words, media (Posner 1986). While language, rooted in reason (logos), has been traditionally regarded as the essential anthropological basis of conveyance, we are critical of regarding it as a universally established apparatus for exploring and structuring the world (Vogel 2001). In our opinion, the role of cultural conveyance can be attributed to different media (Sachs-Hombach 2013, Schirra \& Sachs-Hombach 2006). Ambiguity, therefore, necessarily has media-specific forms. The investigation of these forms is especially important, as each medium is characterized by very different ability profiles, and because ambiguity takes on different forms depending on the medium being used, making a comparative analysis of media forms necessary. If, like Wittgenstein, we treat ambiguity as a phenomenon of aspect perception, we can also investigate to what extent the different aspects of understanding utterances with a double or multiple meaning are the result of interpretative requirements or perceptual mechanisms, and to what extent not only cultural influences, but also intercultural, anthropological constants are hereby relevant for the choice of each aspect.

\section{Semantic Levels of Ambiguity}

It is not sufficient to distinguish between different types and media forms of ambiguity when trying to achieve a complete understanding of constitutive ambiguity. Ambiguity also has different effects in different dimensions of the communication process. First, it can be found on the level of content (content, applied to language, being understood as lexical meaning). The example of 'Hermann the hermaphrodite,' for instance, allows us to ascribe two types of competing content, namely male aspects and female aspects. This is why wit in general (Grimmelshausen's in particular) is a good example of constitutive ambiguity on the lexical or content level. 
In addition to content, the referential level is also important. It does make a difference whether signs display ambiguity in their content-related meaning or in their reference. Expressions with a nominal function, for instance proper names, can be unambiguous in terms of content, but ambiguous in terms of reference. For instance, a photograph of a person who has a twin sibling can be ambiguous as to which one of the twins it is referring, even though the content of the photograph, in other words a particular person's appearance, can be clearly described.

Concerning the general complexity of ambiguity in communicative processes, we have to take into account not only the content and reference - and this is our main argument here - but also the pragmatic level, in other words, the level of the meaning of the utterance (Wunderlich 1976). Following intentionalist semantics, we deduct the meaning of the utterance by looking at a specific utterance in light of the speaker's intention. The meaning of an utterance is, thus, based on ascribing or interpreting the communicative intentions (Grice 1957, Meggle 1990, see also the relevance theory according to Sperber \& Wilson 1986). By also putting ambiguity on the level of determining intentions, we take the decisive step of broadening the concept of ambiguity to include the field of constitutive ambiguity in all its performative complexity.

From the point of view of communication theory, we would like to conclude that constitutive ambiguity appears to function as a performative phenomenon on the level of utterance meaning in a way that is relevant for society while it also presupposes competing determinations of communicative intentions or communicative purposes.

\section{Conclusion}

According to our argument, a general theory of ambiguity should be rooted in cultural anthropology, or rather, to be precise, the anthropology of media. Essentially, the assumed connection between ambiguity, media, and culture is anthropologically motivated. As all humans are exposed to other cultures (Plessner 1928), culture functions as a specific (second) nature that humans, as animalia symbolica (Cassirer 1944), rely on in order to continuously adapt their social behavior to a changing environment (Tomasello 2009). That is why culture provides the necessary background, making prototypical images, scenes, and narratives available to each individual member of a society for better action control. The constitutive aspectual character and restriction of relevance as to what is conveyed through the media acquires its theoretical meaning through its conveyance, which must be continually updated throughout history (Seel 1998, 253). 
That is why an anthropology of media can be divided into the two perspectives of analyzing media according to communicative, or evolutionary points of view.

An anthropology of media based on communication theory understands ambiguity as a specific phenomenon of communicative action. Accordingly, the communicative requirements that ensure a structural framework for a general theory of ambiguity can be laid out in detail. These requirements include, for instance, the basic assumptions of speech act theory, relevance theory, as well as broader conceptions of communicative action, as developed by Habermas (1981). Ambiguity can also be understood as an evolutionary strategy of enculturation. In this case, media anthropology also serves as an anthropological theory. If this presupposes the use of media in the formation of modern human beings and in the further development of cultural standards, then it also implies that all cultures must develop their own ways of dealing with ambiguity as a sophisticated form of open communication. We can assume that cultures that are more tolerant towards ambiguity will have greater variability in the hermeneutical processing of ambiguity and, thus, develop an evolutionary advantage that can help them to better tackle cultural challenges. We believe that one argument in favor of this is that communication is more than, occasionally different from, and never only the conveyance of, information. It primarily serves social functions. Both the social cohesion within a group as well as the strategic positioning of the individual within a group is conveyed through communication.

The connection between the communicative and evolutionary aspects of an anthropology of media is revealed when ambiguity is intentionally used as a strategic tool. Ambiguity can be used intentionally, for example, when producing specific communicative utterances in order to conceal the intended reading behind another official reading avoiding undesirable consequences. Ambiguity can also be used by the recipient in order to create freedom of interpretation and to avoid an assumed dominant reading. In the context of an anthropology of media, a proposed general theory of ambiguity should take into account the different strategic functions of ambiguity and analyze them according to their respective rationality. From the evolutionary point of view, it has in no way been settled that unambiguity in communication is always an advantage. If unambiguity can only be achieved with great effort, then it would seem to be actually an evolutionary advantage to abstain from unambiguity for the benefit of the efficient use of the means of communication. The Oracle of Delphi could, therefore, be regarded as an instrument of enculturation that served an important function for the political development of ancient Greece by skilfully dealing with ambiguity (in other words, practicing tolerance for ambiguity).

Putting emphasis on the strategic use of ambiguity most certainly directs our attention to the cultural role fulfilled by conflicts of meaning and, thus, 
emphasizes the connection between power, identity, and cultural development. With respect to cultural studies, the point of view of the intentionalist theory of meaning, which interprets functioning communication as the convergence of what was meant by the "addresser" and what was understood by the "addressee," should, however, be reversed. The communicative and cultural anthropological function of ambiguity is, in many cases, actually based on the (open or hidden) incongruity between these two entities. It can be seen as either implicit or explicit. The use of implicit ambiguity makes it possible to either disguise or resist power. In contrast, the use of explicit ambiguity is a political tool that either reinforces or obstructs hegemonic meanings.

In consequence, the research of ambiguity employs very different systems of categories to describe phenomena of ambiguity. The phenomenon of competing meanings in an insufficient context (i-ambiguity, or hermeneutic ambiguity) can be seen as the standard form of ambiguity. This type of ambiguity is most likely the result of an effective use of the means of communication, as it is apparently very economical not to refer to contexts explicitly but to implicitly take them for granted, or to only make them explicit if this is relevant to the aims of communication. This type of ambiguity is rather unproblematic and can actually be resolved with little effort. It has been our aim here to point out another type of ambiguity which we have labelled constitutive ambiguity and which we have discussed primarily as a pragmatic phenomenon. Unlike interpretative ambiguity, constitutive ambiguity has simultaneously competing interpretations. According to our argument, this simultaneity is applied, in the use of constitutive ambiguity, as a communication strategy, in order to prevent an unambiguous communication situation. Each (communicative) action, indeed, becomes more flexible something that we believe can be regarded as an advantage from an evolutionary perspective.

\section{References}

Bauer, Matthias, Joachim Knape, Peter Koch \& Susanne Winkler (2010) Dimensionen der Ambiguität. In: Wolfgang Klein \& Susanne Winkler (eds.) Zeitschrift für Literaturwissenschaft und Linguistik 158, 7-75.

Berndt, Frauke \& Stephan Kammer (eds.) (2009) Amphibolie - Ambiguität - Ambivalenz. Würzburg: Königshausen \& Neumann.

Cassirer, Ernst (1944) An Essay on Man. Introduction to a Philosophy of Human Culture. New Haven: Yale University Press.

Eco, Umberto (1989) The Open Work. Cambridge, MA: Harvard University Press.

Ernst, Martin (2003) Syntaktische Ambiguität. Eine sprachübergreifende Typisierung auf der Basis des Französischen und Spanischen. Frankfurt am Main: Peter Lang. 
Fries, Norbert (1980) Ambiguität und Vagheit. Tübingen: Niemeyer.

Gamboni, Dario (2002) Potential Images, Ambiguity and Indeterminacy in Modern Art. London: Reaktion Books.

Grice, Herbert Paul (1957) Meaning. Philosophical Review 64, 377-388.

Grimmelshausen, Hans Jakob Christoffel von (1912) The Adventurous Simplicissimus. Being the Description of the Life of a Strange Vagabond Named Melchior Sternfels von Fechsheim. London: William Heinemann.

Habermas, Jürgen (1981). Theory of Communicative Action. Boston: Beacon Press.

Haverkamp, Anselm (2012) Die Zweideutigkeit der Kunst. Zur historischen Epistemologie der Bilder. Berlin: August.

Krieger, Verena \& Rachel Mader (eds.) (2010) Ambiguität in der Kunst. Typen und Funktionen eines ästhetischen Paradigmas. Köln, Weimar, Wien: Böhlau.

Meggle, Georg (1990) Intention, Kommunikation und Bedeutung. Eine Skizze. In: Forum für Philosophie Bad Homburg (ed.) Intentionalität und Verstehen. Bad Homburg, Frankfurt am Main: Suhrkamp, 88-108.

Plessner, Helmuth (1928) Die Stufen des Organischen und der Mensch. Einleitung in die philosophische Anthropologie. Berlin, New York: de Gruyter.

Posner, Roland (1986) Zur Systematik der Beschreibung verbaler und nonverbaler Kommunikation. In: Hans-Georg Bosshardt (ed.) Perspektiven auf Sprache. Interdisziplinäre Beiträge zum Gedenken an Hans Hörmann. Berlin, New York: de Gruyter, 267-313.

Richards, Ivor A. (1936) The Philosophy of Rhetoric. New York, London: Oxford University Press.

Sachs-Hombach, Klaus (2013) Das Bild als kommunikatives Medium. Elemente einer allgemeinen Bildwissenschaft. Köln: Halem.

Scheffler, Israel (1979) Beyond the Letter. A Philosophical Inquiry into Ambiguity, Vagueness and Metaphor in Language. London: Routledge \& Kegan Paul.

Scheffler, Israel (1989) Pictorial Ambiguity. Journal of Aesthetics and Art Criticism 47.2, 109-115.

Schirra, Jörg R. J. \& Klaus Sachs-Hombach (2006) Fähigkeiten zum Bild- und Sprachgebrauch. Deutsche Zeitschrift für Philosophie 54, 887-905.

Schulz von Thun, Friedemann (1981-1998) Miteinander reden. Reinbek bei Hamburg: Rowohlt. Seel, Martin (1998) Medien der Realität und Realität der Medien. In: Sybille Krämer (ed.) Medien - Computer - Realität. Frankfurt am Main: Suhrkamp, 244-268.

Sperber, Dan \& Deirdre Wilson (1986) Relevance. Communication and Cognition. Oxford: Blackwell.

Tomasello, Michael (2009) Die Ursprünge der menschlichen Kommunikation. Frankfurt am Main Main: Suhrkamp.

Vogel, Matthias (2001) Medien der Vernunft. Eine Theorie des Geistes und der Rationalität auf Grundlage einer Theorie der Medien. Frankfurt am Main: Suhrkamp.

Waldenfels, Bernhard (1987) Ordnung im Zwielicht. Frankfurt am Main: Suhrkamp.

Wunderlich, Dieter (1976) Studien zur Sprechakttheorie. Frankfurt am Main: Suhrkamp. 